\title{
KONTRIBUSI PEKERJA PEREMPUAN TERHADAP PENDAPATAN KELUARGA PETANI DI DESA KOPIWANGKER KECAMATAN LANGOWAN BARAT
}

\begin{tabular}{ll} 
& $\begin{array}{c}\text { Natalia Deisi Yulandri Tumoka } \\
\text { Olly Esry Harryani Laoh } \\
\text { Welson Marthen Wangke }\end{array}$ \\
& \\
\hline $\begin{array}{l}\text { Naskah diterima melalui Website Jurnal Ilmiah agrisosioekonomi@ unsrat.ac.id } \\
\text { Disetujui diterbitkan }\end{array}$ & : Jumat, 12 Juli 2019 \\
: Kamis, 25 Juli 2019 \\
\hline
\end{tabular}

\begin{abstract}
The purpose of the study was to find out how much the contribution of female workers to the income of farmer families in Kopiwangker Village, West Langowan District. The study lasted for two months, starting from October to November 2016. The sampling method was carried out in a simple randomized manner with the number of respondents as many as 30 people. This study used primary data and secondary data. Primary data obtained through direct interviews with respondents based on a list of questions that have been prepared. Secondary data was obtained directly from the Head of Village Office of Kopiwangker Village, West Langowan Subdistrict, and internet through google books and google scholars to obtain journal articles and theses related to the topic of this research, namely the contribution of female workers to the income of farmer families. The data obtained were analyzed descriptively and presented in table form. To find out the contribution of female workers to the income of the farmer family, a contribution formula is used. The research results showed that the average income contribution percentage of female workers in Kopiwangker Village income to the family was $35.47 \%$ with an average income of $R p$ 1,233,333.33. The time allocation to spent on productive activities is 43.95 hours / month. ${ }^{*}$ eprm*
\end{abstract}

Keywords: contribution, female workers, farmer family income

\begin{abstract}
ABSTRAK
Tujuan penelitian yaitu untuk mengetahui berapa besar kontribusi pekerja perempuan terhadap pendapatan keluarga petani di Desa Kopiwangker Kecamatan Langowan Barat. Penelitian berlangsung selama dua bulan yakni mulai bulan Oktober sampai November 2016. Metode pengambilan sampel dilakukan secara acak sederhana dengan jumlah responden sebanyak 30 orang. Penelitian ini menggunakan data primer dan data sekunder. Data primer diperoleh melalui wawancara langsung dengan responden bedasarkan daftar pertanyaan yang telah disiapkan. Data sekunder diperoleh langsung dari Kantor Hukum Tua Desa Kopiwangker Kecamatan Langowan Barat, dan internet google books dan google scholars untuk mendapatkan artikel jurnal dan skripsi yang berkaitan dengan topik penelitian ini yaitu kontribusi pekerja perempuan terhadap pendapatan keluarga petani. Data yang diperoleh dianalisis secara deskriptif dan disajikan dalam bentuk tabel. Untuk mengetahui kontribusi pekerja perempuan terhadap pendapatan keluarga petani digunakan rumus kontribusi. Hasil penelitian menunjukkan bahwa rata-rata persentase kontribusi pendapatan pekerja perempuan di Desa Kopiwangker pendapatan terhadap keluarga sebesar 35,47\% dengan rata - rata pendapatan sebesar Rp 1.233.333,33. Alokasi waktu yang digunakan untuk kegiatan produktif
\end{abstract} sebesar 43,95 jam/bulan. ${ }^{*}$ eprm*

Kata kunci : kontribusi, pekerja perempuan, pendapatan keluarga petani 


\section{PENDAHULUAN}

\section{Latar Belakang}

Sektor pertanian merupakan penopang tertinggi dalam pendapatan negara serta menjadi mata pencaharian sebagian masyarakat Indonesia mengingat wilayah kita yang kaya akan lahan, subur, dan iklim mendukung. Menghasilkan produk pertanian yang berkualitas merupakan komoditi terbesar Negara Indonesia yang menduduki posisi teratas dalam Badan Pusat Statistik terhadap perhitungan Produk Domestik Bruto di Indonesia tiap tahunnya. Untuk itu perlu adanya perhatian khusus terhadap sektor pertanian ini guna peningakatan hasil tani ditahun-tahun kedepannya dengan melihat berbagai faktor kendala seperti masalah minimnya modal para petani, masalah kepemilikan lahan, maupun ketidakmampuan dalam penggunaan alat yang berteknologi canggih menjadi perhatian khusus dalam penanganannya mengenai sektor pertanian tersebut sehingga perlu adanya partisipasi dan dukungan dari pihak pemerintah maupun kepedulian segenap masyarakat dalam menangani kasus tersebut. Dalam masalah kepemilikan lahan pemerintah beserta masyarakat harus tururt membela hak lahan milik petani guna menjaga kelangsungan lingkungan dan pengolaan lahan untuk kegiatan pertanian. Pembangunan yang berkelanjutan pula harus memperhatikan segi lingkungan alam yang ada di wilayahnya jangan sampai memakan wilayah pertanian dan merusak kondisi lingkungan kita. Masalah kepemilikan modal pula perlu dibentuknya sejenis koperasi petani, organisasi tani, serta modal simpan pinjam bagi rakyat kecil.

Produk domestik bruto adalah nilai pasar semua barang dan jasa yang diproduksi oleh suatu negara pada periode tertentu. Produk domestic bruto merupakan salah satu metode untuk menghitung pendapatan nasional.

Badan Pusat Statistik adalah Lembaga Pemerintah Non Kementerian yang bertanggung jawab langsung kepada Presiden. Sebelumnya, BPS merupakan Biro Pusat Statistik, yang dibentuk berdasarkan UU Nomor 6 Tahun 1960 tentang Sensus dan UU Nomer 7 Tahun 1960 tentang Statistik.
Pembangunan yang berkelanjutan pula harus memperhatikan segi lingkungan alam yang ada diwilayahnya jangan sampai memakan wilayah pertanian dan merusak kondisi lingkungan kita. Masalah kepemilikan modal pula perlu dibentuknya sejenis koperasi petani, organisasi tani, serta modal simpan pinjam bagi rakyat kecil guna membantu kegiatan para petani dalam pengeloaan lahan mulai dari pemberian bibit unggul, pemberiaan pupuk, hingga memperoleh hasil akhir dari pertanian yaitu ketika tiba musim panen yang memang membutuhkan modal yang tidak sedikit.

Perlu pula adanya penyuluhanpenyuluhan yang dilakukan oleh pemerintah dan masyarakat guna meningkatkan semangat para petani dalam pengeloaan lahan, penyampaian informasi tani yang tepat dalam peningkatan hasil pangan, cara-cara mengkreasikan hasil tani, serta cara-cara penggunaan alat-alat teknologi canggih guna mendapatkan hasil yang optimal dari kegiatan bertani dengan efektif dan efisien tanpa memakan waktu lama dan tenaga yang besar serta dengan modal yang sekecil-kecilnya sesuai dengan prinsip ekonomi.

Fenomena perempuan bekerja di sektor pertanian bagi masyarakat bukan sesuatu hal yang baru. Sejarah menunjukkan bahwa asal mula pertanian berawal dari pembagian kerja antara pria dan perempuan, dimana pria melakukan pekerjaan berburu dan meramu hasil hutan, sedangkan perempuan bertani di sekitar rumah dan mengerjakan pekerjaan rumah tangga. Semakin maju masyarakat maka usaha pertanian dilakukan secara menetap dan dilakukan oleh pria dan perempuan. Masuknya tenaga kerja perempuan ke sektor pertanian di dorong oleh kebutuhan pokok masyarakat (Sukesi, 2002).

Perempuan merupakan sumber daya insani yang potensial dalam pembangunan. Potensi kaum perempuan yang relatif besar sudah di manfaatkan secara maksimal terutama dalam kegiatan-kegiatan produktif, seperti bekerja atau melakukan suatu kegiatan dengan tujuan untuk memperoleh pendapatan atau penghasilan namun belum diekspos didalam media-media cetak sehingga dikenal oleh masyarakat luas dan yang diekspos hanyalah 
tenaga kerja pria selaku kepala rumah tangga. Selain itu, peran perempuan tidak terlepas dari fungsi sebagai ibu rumah tangga, istri pendamping suami, serta pembina putra dan putri. Peranan perempuan dalam kehidupan keluarga semakin berkembang (Sumarsono, 2009).

Saat ini, perempuan tidak saja melakukan kegiatan di dalam lingkup keluarga, tetapi banyak di antara bidang-bidang kehidupan masyarakat yang membutuhkan kehadiran perempuan dalam penanganannya. Ikut sertanya perempuan dalam kegiatan ekonomi bukan sesuatu hal yang baru. Perempuan berusaha memperoleh penghasilan yang disebabkan oleh beberapa hal, antara lain adanya kemauan perempuan untuk mandiri dalam bidang ekonomi, yaitu berusaha membiayai kebutuhan hidupnya dan kebutuhan hidup dari orang-orang yang menjadi tanggungannya. Selain itu, adanya kebutuhan untuk menambah penghasilan keluarga serta semakin meluasnya kesempatan kerja yang menyerap tenaga kerja perempuan juga merupakan salah satu faktor pendorong perempuan untuk bekerja (Sumarsono, 2009).

Di Kecamatan Langowan Barat, pekerja petani sebagian besar berasal dari daerah tersebut. Tidak hanya petani pria yang terlibat dalam kegiatan bertani, tetapi juga perempuan yang ikut berperan penting dalam kegiatannya. Salah satu desa di Kecamatan Langowan Barat yang pekerjanya perempuan tani adalah Desa Kopiwangker. Keterbatasan sumber daya alam dan luas lahan yang terbatas. Sehingga petani bekerja dilahan milik orang lain dan ada yang bekerja diluar bidang pertanian, sehingga banyak pekerja perempuan di Desa Kopiwangker, jumlah penduduk di desa kopiwangker kecamatan langowan barat adalah 342 kepala keluarga dan luas lahan keluarga 62 ha. Bahwa setiap keluarga memiliki rata-rata 0,18 $\mathrm{Ha} /$ keluarga, kegiatan bertani telah dilakukan sejak lama dan turun temurun oleh masyarakat Desa Kopiwangker yang mayoritas bekerja dibidang pertanian. Rata-rata perempuan yang bekerja sebagai petani adalah mengolah lahan pertanian yang bukan milik sendiri dan selain perempuan bekerja dibidang pertanian, ada yang bekerja diluar bidang pertanian. Kaum pria juga mempunyai peran penting dalam bekerja dibidang pertanian. Hal ini ditandai dengan peran serta atau pria dalam mengolah lahan, pemupukan, panen dan pasca panen. Kerja sama yang baik antara pria dan perempuan akan mendapatkan hasil yang memuaskan.

\section{Rumusan Masalah}

Berdasarkan latar belakang, maka rumusan masalah dalam penelitian ini adalah Berapa Besar Kontribusi Pekerja Perempuan Terhadap Pendapatan Keluarga Petani Di Desa Kopiwangker Kecamatan Langowan Barat?

\section{Tujuan Penelitian}

Tujuan penelitian yaitu untuk mengetahui berapa besar kontribusi pekerja perempuan terhadap pendapatan keluarga petani di Desa Kopiwangker Kecamatan Langowan Barat.

\section{Manfaat Penelitian}

Penelitian ini dapat bermanfaat sebagai masukan bagi pembinaan, pembuat kebijakan program, pemberdayaan masyarakat dan tambahan informasi tentang kontribusi pekerja perempuan terhadap pendapatan keluarga petani serta sebagai tambahan penghasilan dalam keluarga.

\section{METODE PENELITIAN}

\section{Lokasi dan Waktu Penelitian}

Penelitian ini telah dilaksanakan di Desa Kopiwangker Kecamatan Langowan Barat. Pemilihan lokasi penelitian berdasarkan kriteria bahwa di Desa ini banyak perempuan yang bekerja dibidang pertanian dan diluar bidang pertanian. Berlangsung selama dua bulan yakni mulai bulan Oktober 2016 sampai November 2016 yang dimulai dari persiapan sampai dengan laporan hasil penelitian.

\section{Metode Pengumpulan Data}

Penelitian ini menggunakan data primer dan data sekunder. Data primer diperoleh melalui wawancara langsung dengan responden berdasarkan daftar pertanyaan yang telah disiapkan, sedangkan data sekunder diperoleh langsung dalam dari Kantor Hukum Tua Desa Kopiwangker Kecamatan Langowan Barat.

Agrisosioekonomi:

Jurnal Transdisiplin Pertanian (Budidaya Tanaman, Perkebunan, Kehutanan, Peternakan, Perikanan), Sosial dan Ekonomi 


\section{Metode Pengambilan Sampel}

Populasi dalam penelitian ini adalah seluruh keluarga mempunyai anggota pekerja perempuan di Desa Kopiwangker Kecamatan Langowan Barat. Saat ini tercatat sebanyak 74 keluarga sebagai populasi. Jumlah sampel sebagai responden yaitu sebanyak 30 keluarga yang diambil secara simple random sampling acak sederhana.

\section{Konsep Pengukuran Variabel}

Variabel-variabel yang diukur dalam penelitian ini, adalah :

1. Karakteristik responden dalam hal ini perempuan pekerja petani berupa umur (tahun), tingkat pendidikan (tamatan SD, SMP, SMA), jumlah tanggungan keluarga (orang), pekerjaan suami dan anggota keluarga lain.

2. Pendapatan perempuan pekerja yaitu pendapatan yang diperoleh dari berbagai pekerjaan yang dijalankan, yang dihitung berdasarkan (Rp/bulan).

3. Pendapatan keluarga dihitung berdasarkan:

a. Pendapatan istri yaitu pendapatan ibu rumah tangga yang didapat dari hasil bertani (Rp/bulan)

b. Pendapatan suami yaitu pendapatan yang diperoleh dari berbagai pekerjaan yang dijalankan, yang dihitung berdasarkan (Rp/bulan)

c. Pendapatan anak yaitu dari anak lakilaki dan perempuan yang belum menikah tetapi sudah bekerja (Rp/bulan).

\section{Analisis Data}

Data yang diperoleh dianalisis secara deskriptif (desciptive analysis) (Sugiyono, 2003). Semua data yang dianalisis disajikan dalam bentuk tabel dan untuk mengetahui kontribusi pekerja perempuan terhadap pendapatan keluarga petani digunakan rumus:

Kontribusi Pekerja Perempuan $\frac{\text { Pendapatan pekerja Perempuan }}{\text { Pendapatan Keluarga }} \times 100 \%$

(Pendapatan Keluarga $=$ PendapatanSuami + Pendapatan Istri + Pendapatan anak dan perempuan yang sudah bekerja)

\section{HASIL DAN PEMBAHASAN}

\section{Deskripsi Lokasi Penelitan \\ Keadaan Geografis Lokasi Penelitian}

Desa Kopiwangker adalah salah satu desa dari 16 (enam belas) desa yang ada di Kecamatan Langoan Barat Kabupaten Minahasa Provinsi Sulawesi Utara dengan jarak ke Pusat Kabupaten $26 \mathrm{Km}$. Desa Kopiwangker terdiri dari 4 jaga dan berada di ketinggian tanah dari permukaan laut $702 \mathrm{mdpl}$, suhu rata - rata $30 \mathrm{OC}$ dengan luas wilayah $+62 \mathrm{Ha}$ yang terdiri dari Pemukiman $20 \mathrm{Ha}$, Sawah $35 \mathrm{Ha}$, Ladang 5 Ha dan Lain-lain 2 Ha. berikut:

Adapun batas-batasnya adalah sebagai

a. Sebelah Utara dengan desa Taraitak Kecamatan Langowan Utara

b. Sebelah Timur Desa Paslaten

c. Sebelah Selatan Desa Walewangko dan Desa Lowian

d. Sebelah Barat Desa Tumaratas dan Desa Ampreng.

\section{Keadaan Penduduk Lokasi Penelitian}

Tabel 1 menunjukkan bahwa penduduk Desa Kopiwangker berjumlah penduduk sebesar 1050 jiwa penduduk laki-laki sebanyak 551 lebih banyak dari perempuan yaitu $52.48 \%$ dan perempuan 499 jiwa dengan persentase sebesar $47.52 \%$.

\begin{tabular}{|c|c|c|c|}
\hline No & Jenis Kelamin & Jumlah (orang) & Persentase (\%) \\
\hline 1 & Laki-laki & 551 & 52.48 \\
\hline 2 & Perempuan & 499 & 47.52 \\
\hline & Jumlah & 1050 & 100.00 \\
\hline
\end{tabular}

\section{Karakteristik Responde Umur}

Tabel 2 menunjukkan bahwa umur responden terbanyak pada kategori 40 sampai 50 dengan persentase $30 \%$ dan paling rendah pada kategori dibawah umur 30 dan umur 50 sampai 60 tahun dengan persentase sama yaitu $10 \%$.

Tabel 2. Umur dan Jumlah Responden di Desa Kopiwangker

\begin{tabular}{cccc}
\hline No & Umur & Jumlah Responden & Persentase $(\%)$ \\
\hline 1 & $>30$ & 3 & 10.00 \\
2 & $31-40$ & 8 & 26.67 \\
3 & $41-50$ & 9 & 30.00 \\
4 & $51-60$ & 7 & 23.33 \\
5 & $>61$ & 3 & 10.00 \\
\hline Jumlah & & 30 & 100 \\
\hline
\end{tabular}

Sumber data : Diolah dari data Primer, 2018 


\section{Tingkat Pendidikan}

Tabel 3 menunjukkan tingkat pendidikan responden tertinggi pada pendidikan SMA dengan persentase sebesar $33,33 \%$ dan terendah pada tingkat pendidikan $\mathrm{S} 1$ dengan persentase sebesar $6,67 \%$.

\begin{tabular}{cccc}
\multicolumn{6}{l}{ Tabel 3. Tingkat Pendidikan Responden } \\
\hline No & Pendidikan & Jumlah Responden & Persentase $(\%)$ \\
\hline 1 & SD & 8 & 26.67 \\
2 & SMP & 9 & 30.00 \\
3 & SMA & 10 & 33.33 \\
4 & D3 & 1 & 3.33 \\
5 & S1 & 2 & 6.67 \\
\hline \multicolumn{7}{l}{ Sumber data : Diolah dari data Primer, 2018 } \\
\hline
\end{tabular}

\section{Jumlah Tanggungan Keluarga}

Tabel 4 menunjukkan bahwa jumlah tanggungan responden tertinggi pada jumlah tanggungan 1 , dengan persentase $50 \%$. Sedangkan terendah pada jumlah tanggungan 4 , dengan persentase $7 \%$.

\begin{tabular}{cccc}
\multicolumn{6}{c}{ Tabel 4. Jumlah Tanggungan Responden } \\
\hline \multirow{2}{*}{ No } & jumlah Tanggungan & $\begin{array}{c}\text { Jumlah } \\
\text { Responden }\end{array}$ & Persentase (\%) \\
\hline 1 & 1 & 15 & 50 \\
2 & 2 & 8 & 27 \\
3 & 3 & 5 & 17 \\
4 & 4 & 2 & 7 \\
\hline \multicolumn{7}{r}{ Sumber data : Diolah dari data Primer, 2018 } \\
\end{tabular}

\section{Jenis Pekerjaan Wanita Keluarga Petani}

Tabel 5 menunjukkkan bahwa jumlah pekerjaan terbanyak adalah buruh tani yaitu Responden 26 dengan persentase $87 \%$ dan yang terendah jenis pekerjaan perangkat Desa dengan persentase $3 \%$.

Tabel 5. Jenis Pekerjaan Perempuan Keluarga Petani di Desa

\begin{tabular}{|c|c|c|c|}
\hline No & Jenis Pekerjaan & Jumlah Responden & Persentase (\%) \\
\hline 1 & Buru Tani & 26 & 87 \\
\hline 2 & Perangkat Desa & 1 & 3 \\
\hline 3 & PNS & 3 & 10 \\
\hline & Jumlah & 30 & 100 \\
\hline
\end{tabular}

Sumber data : Diolah dari data Primer, 2018

\section{Curahan Waktu Pekerja Wanita Di Desa Kopiwangker}

Tabel 6 menunjukkan bahwa curahan waktu kerja perempuan terendah pada pekerjaan buruh Tani dengan persetase sebesar 37,9\%, hal ini menunjukkan perempuan lebih banyak menggunakan waktu kerja pada kegiatan mengurus rumah tangga.
Tabel 6. Curahan Waktu kerja Perempuan di Desa Kopiwangker

\begin{tabular}{cccccc}
\hline No & $\begin{array}{c}\text { Jenis } \\
\text { Pekerjaan }\end{array}$ & $\begin{array}{c}\text { Jumlah } \\
\text { Responden }\end{array}$ & $\begin{array}{c}\text { Rata - rata } \\
\text { Jam Kerja/ } \\
\text { bulan }\end{array}$ & $\begin{array}{c}\text { Rata - } \\
\text { rata } \\
\text { standar } \\
\text { jam } \\
\text { kerja / } \\
\text { Bulan }\end{array}$ & $\begin{array}{c}\text { Kontribusi } \\
\text { Curahan } \\
\text { Waktu } \\
\text { Kerja (\%) }\end{array}$ \\
\hline 1 & Buruh Tani & 26 & 72,69 & 192 & 37,9 \\
2 & Perangkat Desa & 1 & 160 & 192 & 83,3 \\
3 & PNS & 3 & 160 & 192 & 83,3 \\
\hline \multicolumn{5}{l}{ Sumber : Diolah dari Data Primer, 2018 }
\end{tabular}

\section{Pendapatan Keluarga Petani di Desa} Kopiwangker Pendapatan Suami

Tabel 6 menunjukkan bahwa jumlah responden dengan tingkat pendapatan pada interval $\mathrm{Rp}$ 2.000.000 sampai $\mathrm{Rp} 3.000 .000$ merupakan jumlah tertinggi yaitu 21 responden dengan persentase sebesar $70 \%$ dan terendah terdapat pada interval lebih besar dari $\mathrm{Rp}$ 3.000.000 yaitu 3 responden dengan persentase sebesar $10 \%$. Pada penelitian ini yaitu keluarga petani, yaitu pekerja suami adalah sebagai Petani.

Tabel 7. Pendapatan Suami Responden di Desa Kopiwangker

\begin{tabular}{ccr}
\hline $\begin{array}{c}\text { Pendapatan Suami } \\
(\text { Rp/Bulan })\end{array}$ & Jumlah Responden & Persentase (\%) \\
\hline$<1.000 .000$ & 2 & 6,67 \\
$1.000 .000-<2.000 .000$ & 4 & 13,33 \\
$2.000 .000-<3.000 .000$ & 21 & 70,00 \\
$>3.000 .000$ & 3 & 10,00 \\
\hline Jumlah & 30 & 100,00 \\
\hline
\end{tabular}

Sumber : Diolah dari data Primer, 2018

\section{Pendapatan Istri}

Tabel 8 menunjukkan bahwa jumlah responden dengan tingkat pendapatan pada $\mathrm{Rp}$ 1.000.000 sampai $\mathrm{Rp} 2.000 .000$ merupakan jumlah yang tertinggi yaitu 16 Responden dengan persentase sebesar 53,33\% dan terendah terdapat pada $\mathrm{Rp} 2.000 .000$ sampai $\mathrm{Rp}$ 3.000.000 yaitu tidak ada responden yang memiliki jumlah pendapatan tersebut. Pekerja perempuan kebanyakan bekerja sebagai buruh tani.

Tabel 8. Pendapatan Istri Di Desa Kopiwangker

\begin{tabular}{ccr}
\hline $\begin{array}{c}\text { Pendapatan Istri } \\
(\text { Rp/Bulan })\end{array}$ & Jumlah Responden & Persentase $(\%)$ \\
\hline$<1.000 .000$ & 11 & 36,67 \\
$1.000 .000-<2.000 .000$ & 16 & 53,33 \\
$2.000 .000-<3.000 .000$ & 0 & 0,00 \\
$>3.000 .000$ & 3 & 10,00 \\
\hline Jumlah & 30 & 100,00 \\
\hline Sumber Diolah Dari Data Primer, 2018 &
\end{tabular}




\section{Pendapatan anak}

Tabel 9 menunjukkan bahwa jumlah responden tertinggi terdapat pada dibawah $\mathrm{Rp}$ 1.000.000 yaitu jumlah responden sebesar 26 Responden dengan persentase sebesar $86 \%$ dan terendah terdapat pada interval $\mathrm{Rp} 2.000 .000$ sampai Rp 3.000.000 yaitu tidak ada responden yang memiliki pendapatan tersebut. Beberapa anak bekerja sebagai penjual makanan, bekerja toko di Manado.

Tabel 9. Pendapatan Anak Responden Di Desa Kopiwangker

\begin{tabular}{ccr}
\hline $\begin{array}{c}\text { Pendapatan anak } \\
(\text { Rp/Bulan })\end{array}$ & Jumlah Responden & Persentase (\%) \\
\hline$<1.000 .000$ & 26 & 86,67 \\
$1.000 .000-<2.000 .000$ & 3 & 10,00 \\
$2.000 .000-<3.000 .000$ & 0 & 0,00 \\
$>3.000 .000$ & 1 & 3,33 \\
\hline Jumlah & 30 & 100,00 \\
\hline Sumber : Diolah Dari Data Primer, 2018 &
\end{tabular}

\section{Pendapatan Keluarga}

Tabel 10 menunjukkan bahwa Jumlah responden tertinggi terdapat pada diatas $\mathrm{Rp}$ 3.000 .000 yaitu jumlah responden sebesar 21 Responden dengan persentase sebesar $70 \%$ dan terendah terdapat pada dibawah Rp 1.000.000 yaitu tidak ada responden yang memiliki pendapatan tersebut.

Tabel 10. Pendapatan Keluarga Responden di Desa Kopiwangker

\begin{tabular}{ccr}
\hline $\begin{array}{c}\text { Pendapatan Keluarga } \\
(\text { Rp/Bulan })\end{array}$ & Jumlah Responden & Persentase $(\%)$ \\
\hline$<1.000 .000$ & 0 & 0.00 \\
$1.000 .000-<2.000 .000$ & 2 & 6.67 \\
$2.000 .000-<3.000 .000$ & 7 & 23.33 \\
$>3.000 .000$ & 21 & 70.00 \\
\hline Jumlah & 30 & 100.00 \\
\hline Sumber : Diolah Dari Data Primer, 2018 & &
\end{tabular}

\section{Kontribusi Perkerja Wanita terhadap Pendapatan Keluarga}

Tabel 11 menunjukkan bahwa pendapatan pekerja perempuan sangat berkontribusi dalam pendapan keluarga dengan persentase sebesar $35,47 \%$ yaitu rata - rata pendapatan pekerja perempuan sebesar Rp 1.233.333,33. Dengan demikian dapat dikatakan bahwa kontribusi perempuan tergolong kontribusi cukup baik yang masuk dalam kriteria 30\% sampai $40 \%$.
Tabel 11. Kontribusi Pekerja Perempuan Terhadap pendapatan Keluarga di Desa Kopiwangker

\begin{tabular}{rlcr}
\multicolumn{4}{c}{ Keluarga di Desa Kopiwangker } \\
\hline No & Keterangan & Pendapatan (Rp) & Persentase \\
\hline 1 & Pendapatan Suami & $2.026 .666,67$ & 58,29 \\
2 & Pendapatan Istri & $1.233 .333,33$ & 35,47 \\
3 & Pendapatan Anak & $216.666,67$ & 6,23 \\
4 & Pendapatan Lainnya & - & 0,00 \\
\hline \multicolumn{2}{c}{ Jumlah } & Rp 3.476.666,67 & 100,00 \\
\hline
\end{tabular}

Tabel 12 menunjukkan bahwa jumlah waktu pada saat jam kerja yaitu pada jam 08.00 pagi sampai jam 17.00 sore, jumlah jam yang dipakai yaitu sebesar $43,95 \%$ yaitu rata-rata pekerja perempuan bekerja sebagai buruh tani, yang diketahui penulis, pekerja perempuan hanya bekerja pada saat adanya panggilan pekerjaan sebagai buruh tani, pekerjaannya membersihkan lahan, memberikan pupuk, dan menanam tananam tomat, labu, padi.

\begin{tabular}{lr} 
Tabel 12. Rata-rata Kontribusi Curahan Waktu Kerja & \\
\hline Rata -Rata Waktu Kerja & 43.95 \\
Rata-rata Waktu Diluar Kerja & 56.05 \\
\hline Total & 100 \\
\hline Sumber Data: Diolah Dari Data Primer, 2018
\end{tabular}

\section{DAFTAR PUSTAKA}

Sugiyono, 2003. Metode Penelitian Administrasi. Alfabeta. Bandung.

Sukesi, K. MS. 2002. Hubungan Kerja Dan Dinamika Hubungan Gender Dalam Sistem Pengusahaan Tebu Rakyat. Lembaga Penerbitan Fakultas Pertanian Universitas Brawijaya. Malang.

Sumarsono, S. 2009. Teori dan Kebijakan PublikEkonomi Sumber Daya Manusia. Graha Ilmu. Yogyakarta. 